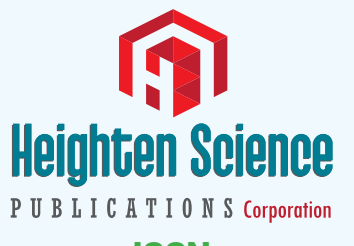

ISSN

2573-7708
*Address for Correspondence: Dr. Wolfgang Freund, Professor, Diagnostic and Interventional Radiology, University Hospitals Ulm, AlbertEinstein-Allee 2389081 Ulm, Germany, Email: freund-ulm@t-online.de

Submitted: 04 March 2016

Approved: 24 March 2017

Published: 27 March 2017

Copyright: $\circledast 2017$ Freund W, et al. This is an open access article distributed under the Creative Commons Attribution License, which permits unrestricted use, distribution, and reproduction in any medium, provided the original work is properly cited.

Keywords: Magnetic resonance imaging; Zygapophysial joint; Facet joint; Spine; Pain

Abbreviations: MRI: Magnetic Resonance Imaging; SPECT: Single Photon Emission Computed Tomography; CT: Computed

Tomography; LR: Likelihood Ratio; SD: Standard Deviation
Research Article

\section{Magnetic Resonance Imaging Can Detect Symptomatic Patients with Facet Joint Pain. A Retrospective Analysis}

\author{
Wolfgang Freund ${ }^{1,2 *}$, Frank Weber ${ }^{3}$, Reinhard Meier ${ }^{1}$ and \\ Stephan Klessinger 4,5 \\ 'Diagnostic and Interventional Radiology, University Hospitals Ulm, Germany \\ ${ }^{2}$ Neurology Outpatient Clinic, Biberach, Germany \\ ${ }^{3}$ German Air Force Center of Aerospace Medicine, Fuerstenfeldbruck, Germany \\ ${ }^{4}$ Neurosurgery, University Hospitals Ulm, Germany \\ ${ }^{5}$ Neurosurgery, Nova Clinic, Biberach, Germany
}

\section{ABSTRACT}

Background: Low back pain has recently been reported as the leading cause for disability worldwide. The diagnostic value of imaging has been estimated low. Led by own positive experience, however, we hypothesized that MRI can detect signs of facet joint pain.

Methods: 15 patients and 15 controls were retrospectively assessed by two readers. They compared deidentified T2 weighted lumbar spine MRI scans. Facet joint size, shape, angle, joint space signal and degeneration were rated. Pain aetiology was proven with the diagnostic gold standard of medial branch blocks.

Results: Facet joint angles and joint diameters were significantly larger in symptomatic patients, who also showed significantly higher grades of degeneration but no difference in joint space distances or shape or signal intensity.

The readers were able to correctly identify symptomatic patients with good interrater reliability (kappa 0.5, sensitivity and specificity $0.87-0.93)$, positive $(L R+=6.7-7.2)$ and negative likelihood ratios $(L R-=0.15)$.

Conclusions: Contrary to recent publications, we could demonstrate differences between asymptomatic and symptomatic subjects showing the latter to have larger joints and more signs of degeneration.

One can conclude from the strong LR+ and LR- values that MRI is a useful investigation to rule in or rule out facet pain.

\section{INTRODUCTION}

Despite being the worldwide leading cause for disability [1], the precise etiology of low back pain is often unclear. Since the costs of low back pain are thought to make it one of the most expensive health issues [2] with costs of over $\$ 90$ billion in the year 1998 in the US [3] efforts at elucidating the causes are worthwhile.

Potential pain generators in the lumbar spine are manifold [4] and the source can often not be specified [5,6]. Besides intervertebral disc degeneration, infection or fracture, degenerative changes in the posterior stabilizing column (facet joints, interspinous ligaments and paraspinal muscles) may be the cause of low back pain 
[7]. Degenerative spondylolisthesis is common and may become more important with aging populations [8]. The proportion of patients with low back pain in whom facet joints are causative has been estimated to be $5-15 \%$ [9] has been shown to increase with age [10] and may amount up to $50 \%$ in chronic pain cohorts [11].

The facet joints protect the intervertebral discs from forward motion [12] or excessive rotational strain [8] and are subjected to higher loads as the discs shrink with age. The form of the facet joints may predispose to mechanical instability.

Mere degeneration is thought not to be pathological [13]. Repetitive stress or cumulative low-level trauma can lead to inflammation and joint capsule distension [9] or inflammatory reactions in the retrodural space of Okada [14].

Clinical signs or tests are thought to be not specific for facet joint pain $[5,9,15]$. Imaging is recommended for chronic lower back pain [16] or in presence of red flag symptoms suggestive of inflammatory or tumorous etiology or neurological deficits [17,18]. Good radiographic diagnostic criteria for facet joint pain are lacking [4]. Furthermore, many asymptomatic patients show facet joint degeneration [4] while other studies show no significant correlation of MRI and disability in facet joint osteoarthritis [19]. Also, the amount of slippage is often underestimated due to the supine position in the scanner. Here, intraarticular fluid in the facet joints can be a sign of instability [20-22]. There exists no single accepted grading scale for facet joint degeneration but a multitude of competing systems [23].

MRI is regarded as the modality of choice for evaluation of lumbar facet joint disease [24], yet it is not recommended in a European guideline [17]. Facet joint activity in SPECT/CT may be discordant from diagnosis $[25,26]$ and CT has been shown to be not helpful $[27,28]$.

To date, the gold standard for the diagnosis of facet joint pain has been shown to consist of repeated controlled anesthetic blocks of the joint innervation $[9,13,29]$. The established technique has been described and recommended by the International Spine Intervention Society [30].

Our own experience with MRI with seemingly good correlation of clinical symptoms and MRI appearance provided the initiative to look for the value of MRI signs in distinguishing patients with proven lumbar facet joint pain from controls.

We hypothesized that MRI is able to detect signs that predict facet joint pain in a sample of 15 patients and 15 controls.

\section{METHODS}

In a retrospective analysis we compared de-identified lumbar spine MRI scans of chronic facet joint pain patients with controls in an outpatient clinic setting. The rules for retrospective and de-identified evaluations of our institutional Ethics Committee were adhered to.

The 15 patients with clinically proven zygapophysial pain ( $>50 \%$ pain relief after controlled medial branch blocks) have been described in detail [31]. 15 consecutive patients of one neurosurgical center presenting with low back pain on one side (left or right) for a minimum of 3 months were included. The pain characteristics had to be suggestive of zygapophysial joint origin. Excluded were patients with radicular pain (e.g., with straight leg test positive) or radiculopathy (motor deficit or sensory changes), with a disc herniation consistent with the complaints, or discitis, spondylodiscitis or an oncologic disease affecting the spine or patients with a history of lumbar spine surgery. Also patients with a spondylolisthesis of Meyerding grade 2 or more were excluded.

15 consecutive controls were selected by means of the electronical medical record 
system of the outpatient clinic. Search term was "normal" in the context of lumbar spine imaging. Exclusion criteria were chronic lumbago or facet joint origin of pain. The control's diagnoses ranged from positional peripheral nerve compression to neuritis or short time lumbago (Table 1).

To facilitate anonymization and exclude possible bias, the examinations were made comparable by exclusion of "unnecessary" scans/levels, so that each subject should include only T2 weighted sagittal and transversal slices (only lumbar 4/5 and lumbosacral levels).

Two readers (WF and SK, each with over 15 years of experience in MRI) blinded to the clinical context rated the examinations independently. The order of presentation was randomized. As described earlier [31], bilaterally and separately facets were evaluated (Figure 1).

\section{Regarding to:}

- joint angle (measured transversely against the sagittal plane, figure 1a),

Table 1: Subjects and clinical symptoms. In the upper part of the table, the controls with normal MRI examinations are listed, the stated diagnosis was the reason for imaging. In the lower part of the table, the patients with zygapophysial pain are listed.

\begin{tabular}{|c|c|c|c|c|c|}
\hline Case $\mathrm{Nr}$ & symptomatic level & side & age & $\operatorname{sex}$ & Diagnosis \\
\hline 2 & $\mathrm{~h}$ & $\mathrm{~h}$ & 25 & M & $\begin{array}{c}\text { Short duration lumbago after home relocation, } \\
\text { remitted }\end{array}$ \\
\hline 5 & $\mathrm{~h}$ & $\mathrm{~h}$ & 28 & M & Peripheral nerve irritation \\
\hline 7 & $\mathrm{~h}$ & $\mathrm{~h}$ & 42 & $\mathrm{~F}$ & $\begin{array}{l}\text { Chronic diffuse pain syndrome (fibromyalgia), } \\
\text { in remission at the end of } 2015\end{array}$ \\
\hline 8 & $\mathrm{~h}$ & $\mathrm{~h}$ & 68 & $M$ & postherpetic neuralgia \\
\hline 10 & $\mathrm{~h}$ & $\mathrm{~h}$ & 38 & $\mathrm{~F}$ & restless legs syndrome \\
\hline 13 & $\mathrm{~h}$ & $\mathrm{~h}$ & 57 & M & ischialgia without MRI correlate \\
\hline 14 & $\mathrm{~h}$ & $\mathrm{~h}$ & 62 & $\mathrm{~F}$ & iliosacral joint pain and trochanteric bursitis \\
\hline 16 & $\mathrm{~h}$ & $\mathrm{~h}$ & 46 & $\mathrm{~F}$ & somatoform pain disorder \\
\hline 19 & $\mathrm{~h}$ & $\mathrm{~h}$ & 33 & $\mathrm{~F}$ & Paresthesia of the feet \\
\hline 20 & $\mathrm{~h}$ & $\mathrm{~h}$ & 51 & $\mathrm{~F}$ & radiculitis of left nerve root S1 \\
\hline 23 & $\mathrm{~h}$ & $\mathrm{~h}$ & 28 & $M$ & inguinal pain, probably coxarthosis \\
\hline 25 & $\mathrm{~h}$ & $\mathrm{~h}$ & 22 & M & $\begin{array}{l}\text { Short time lumbago and movement restriction, } \\
\text { remitted }\end{array}$ \\
\hline 26 & $\mathrm{~h}$ & $\mathrm{~h}$ & 17 & $\mathrm{~F}$ & peripheral nerve compression \\
\hline 28 & $\mathrm{~h}$ & $\mathrm{~h}$ & 35 & $\mathrm{~F}$ & pseudoradicular pain syndrome \\
\hline 30 & $\mathrm{~h}$ & $\mathrm{~h}$ & 27 & $\mathrm{~F}$ & iliosacral joint pain \\
\hline Case $\mathrm{Nr}$ & symptomatic level & side & age & $\operatorname{sex}$ & Diagnosis \\
\hline 1 & 45 & I & 60 & M & Zygapophyseal pain \\
\hline 3 & 51 & $r$ & 63 & $M$ & Zygapophyseal pain \\
\hline 4 & 51 & $r$ & 48 & $M$ & Zygapophyseal pain \\
\hline 6 & 51 & $r$ & 54 & $\mathrm{~F}$ & Zygapophyseal pain \\
\hline 9 & 51 & I & 45 & $\mathrm{~F}$ & Zygapophyseal pain \\
\hline 11 & 51 & I & 51 & $\mathrm{~F}$ & Zygapophyseal pain \\
\hline 12 & 51 & $r$ & 30 & $M$ & Zygapophyseal pain \\
\hline 15 & 51 & I & 22 & $M$ & Zygapophyseal pain \\
\hline 17 & 51 & $r$ & 52 & $\mathrm{~F}$ & Zygapophyseal pain \\
\hline 18 & 45 & I & 56 & $\mathrm{~F}$ & Zygapophyseal pain \\
\hline 21 & 51 & $r$ & 52 & $M$ & Zygapophyseal pain \\
\hline 22 & 51 & $r$ & 51 & $M$ & Zygapophyseal pain \\
\hline 24 & 45 & I & 62 & $\mathrm{~F}$ & Zygapophyseal pain \\
\hline 27 & 45 & I & 81 & $\mathrm{~F}$ & Zygapophyseal pain \\
\hline 29 & 45 & $r$ & 66 & $M$ & Zygapophyseal pain \\
\hline
\end{tabular}

The symptomatic level is given as $h=$ healthy; $45=$ facet joint $L 4 / 5 ; 51=$ facet joint $L 5 / S 1$. The symptomatic side is given as $\mathrm{h}=$ healthy (no facet pain), $\mathrm{l}=$ left or $\mathrm{r}=$ right. The age is given in years. 
- facet joint form (c-shaped, j-shaped or flat, see figure 2),

- largest transversal diameter (Figure 1a),

- smallest joint space distance in the central $80 \%$ of the facet (rounded to $\mathrm{mm}$, see figure 1b),

- joint space signal intensity (hypo- or hyperintense, measured in the median slice, see figure 3),

- degeneration with hypertrophy/osteophytes/erosions (graded as $0=$ normal, $1=$ small $/$ mild, $2=$ moderate, $3=$ large/severe, see figure 4 )

\section{STATISTICAL ANALYSIS}

The radiological measurements, age and sex were regarded as independent variables. Symptom status (symptomatic/asymptomatic) and symptom localization were deemed dependent variables. Descriptive statistical analysis was performed with Microsoft Excel (2003), further analysis was performed with "R" version 3.2.3, R Foundation for Statistical Computing, 2015 [32]. Univariate and multivariate regression analyses were performed and Cohen's kappa was computed.

Results were seen as significant when $\mathrm{p}$ was $<0.05$.

\section{RESULTS}

Chronic facet joint pain patients were older (mean age $53 \mathrm{y}$, SD 14.1) than controls

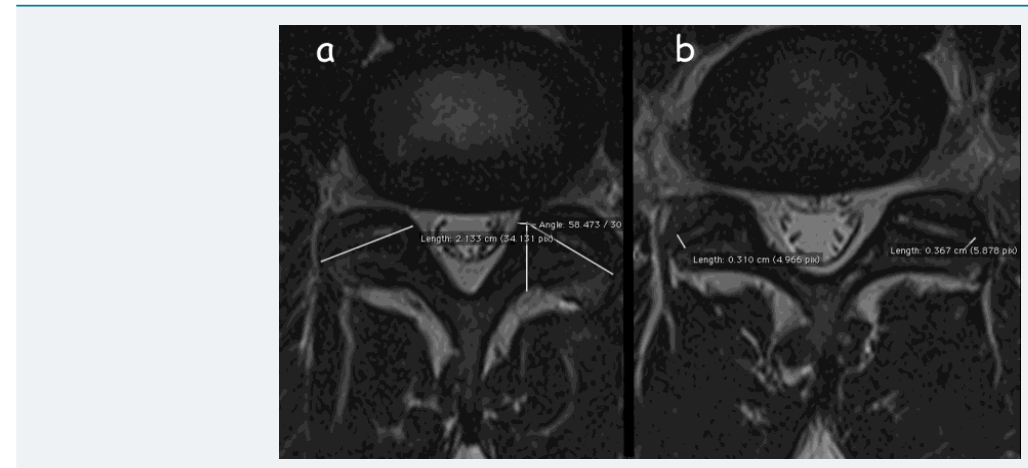

Figure 1: Measurements of zygapophysial joints a) diameter and angle, b) joint space diameter (distances are given in $\mathrm{cm}$, while in table 2 distances are rounded to whole $\mathrm{mm}$ ).

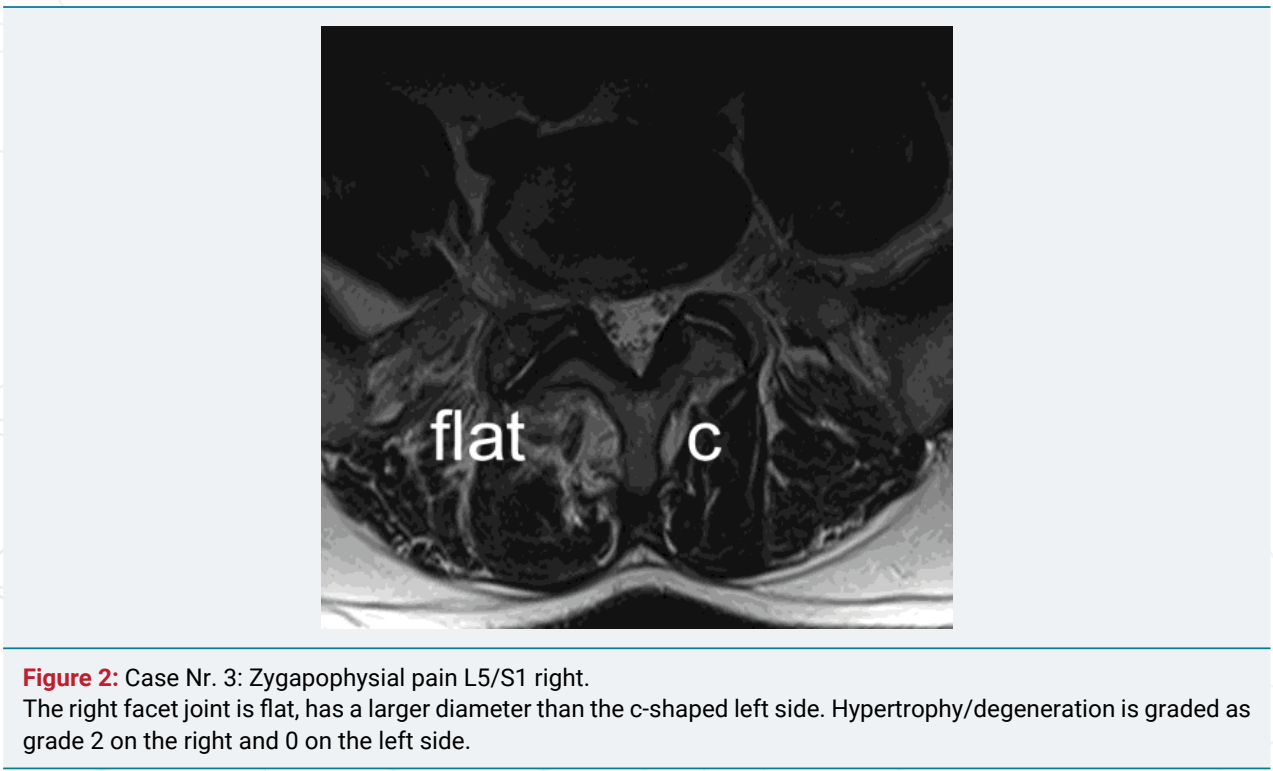


with a mean age of 38 years (SD 15.4, $p=0.01$ ) (Table 1 ). Patients did not significantly differ from controls regarding their sex: Patients were 8 male, 7 female, while controls were 6 male, 9 female.

The measurement of facet joint angles and joint diameters showed significant differences (Table 2) between chronic facet joint pain patients and controls with larger angles at $\mathrm{L} 4 / 5(\mathrm{p}<0.01)$ in patients and larger diameters in patients both at $\mathrm{L} 4 / 5$ and L5/S1 ( $\mathrm{p}<0.001)$. This difference was not due to age, which was confirmed by a regression analysis: A statistically significant $(p=0.007)$ influence of facet joint diameter and angle $(\mathrm{p}=0.02)$, but not of age was shown on symptom status. However, joint space distances were not significantly different for chronic facet joint pain patients and controls $(\mathrm{p}=0.6)$.

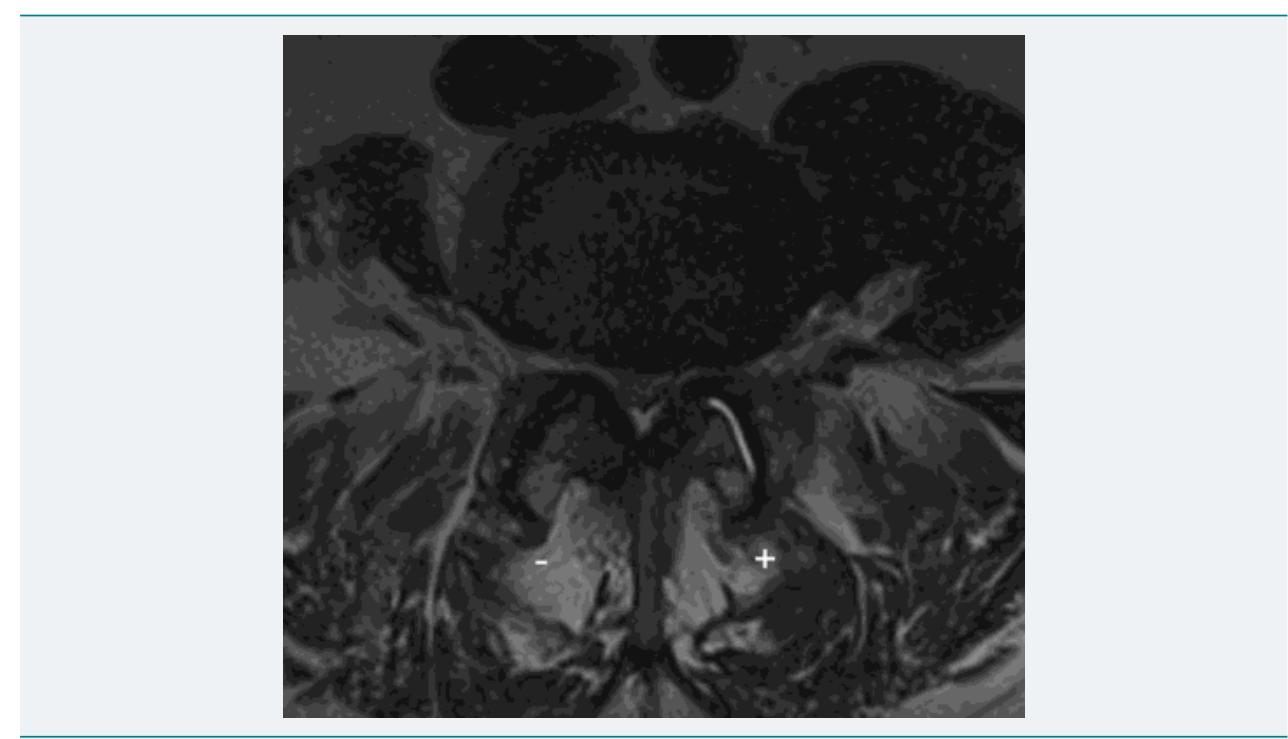

Figure 3: Case Nr 1: Zygapophysial pain L4/5 left.

The right facet joint shows hypointense signal (-) whereas the left side is hyperintense (+). Hypertrophy/degeneration is graded as grade $2-3$ on the right and 2 on the left side.

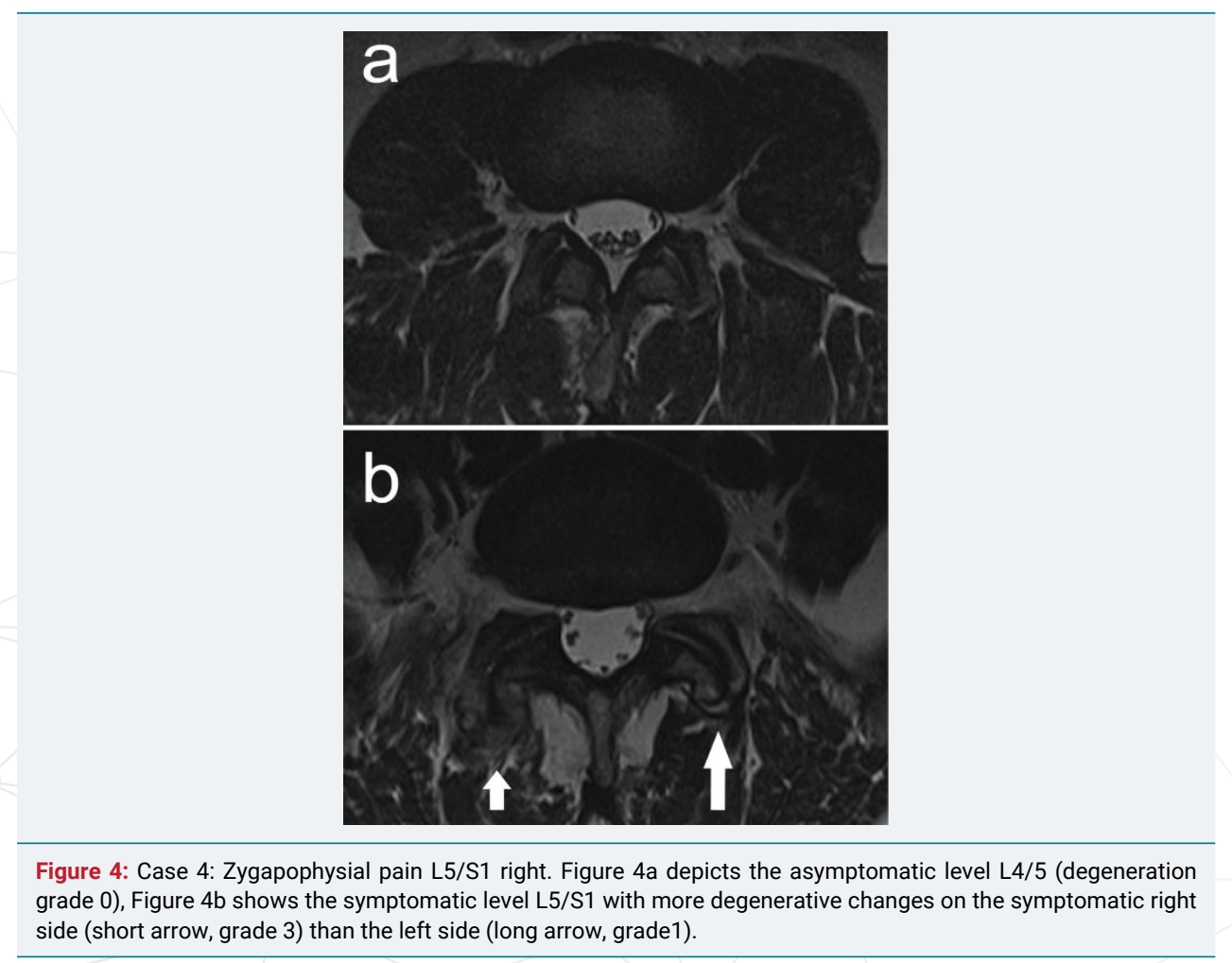


Regarding signs of hypertrophy and degeneration and after correction for age, patients showed significantly $(p=0.03)$ higher grades than controls. Both readers graded chronic facet joint pain patients significantly higher than controls $(p<0.001$ without correction for age).

The readers rated facet joint form congruently in 69\% (kappa 0.32-0.6) and joint space signal congruently and $84 \%$ of the joints (kappa 0.64). Congruently rated joints had an $\mathrm{f}$-shape in $36 \%$, c-shape in $26 \%$ and j-shape in $8 \%$. The joint space was congruently rated as hyperintense in $25 \%$ and as hypointense in $59 \%$ of the joints. However, neither shape $(\mathrm{p}=0.06)$ nor signal intensity $(\mathrm{p}=0.2)$ correlated significantly with symptomatology.

The readers were able to correctly identify chronic facet joint pain patients and controls in all cases (kappa=1) as well as to correctly identify the side in $67-77 \%$ (kappa $=0.43$ ) and height in 77\% (kappa=0.44) of the symptomatic facet joint, resulting in excellent [33] inter-reader reliability regarding differentiation of conrols and patients, moderate inter-reader reliability for spatial identification. The results are shown in table 3. Positive (LR+) and negative likelihood ratios (LR-) can be computed: For the simple distinction between symptomatic patients and controls, the LR+ is 6.77.2 and the LR- is 0.15 .

\section{DISCUSSION}

Contrary to recent publications, we could demonstrate differences between patients with chronic facetogenic pain and controls and show interesting discrepancies regarding facet joint MRI measurements. Especially the grading for degeneration and measurement of facet joint angles at $\mathrm{L} 4 / 5$ differed. Concerning the importance of facet joint disease in the etiology of low back pain and the massive load of back pain on global burden of disease [1], even small contributions of MRI to the definition of etiology are important. The single aspects of our results will be discussed below.

Correctly differentiating chronic facet joint pain patients from controls. The literature is rather pessimistic regarding diagnosis of low back pain: "None of the tests for facet joint pain were found to be informative." [5]. CT has been said to have no place in the diagnosis of facet joint pain [27]. Other promising modalities such as SPECT/CT have shown discordance with therapeutic decisions in clinical settings [25]. Repeated controlled medial branch blocks, however, are the established gold standard for diagnosis of facet joint pain [34,29].

Sensitivity and specificity against this gold standard as well as inter-reader reliability

Table 2: Facet joint measurements of chronic facet joint pain patients and controls.

\begin{tabular}{|c|c|c|c|c|c|c|c|}
\hline Facet joints & & L 4/5 & & & L5/S1 & & \\
\hline & & Angle & Jdiameter & JSDiameter & Angle & Jdiameter & JSDiameter \\
\hline \multirow[t]{2}{*}{ controls } & Mean & 46.6 & 18 & 3.5 & 53.3 & 18.7 & 3.5 \\
\hline & SD & 6.4 & 1.6 & 0.5 & 8 & 1.9 & 0.7 \\
\hline $\begin{array}{l}\text { facet joint pain } \\
\text { patients }\end{array}$ & Mean & 52 & 21 & 3.4 & 55.4 & 21.6 & 3.5 \\
\hline- & SD & 10.7 & 1.9 & 0.8 & 12.6 & 3.1 & 0.7 \\
\hline & $\mathrm{p}$ (t-Test) & $<0.01$ & $<0.0001$ & 0.8 & 0.55 & $<0.001$ & 0.92 \\
\hline
\end{tabular}

Abbreviations: JDiameter: Diameter of the facet joint, JSDiameter: Joint space measured as the smallest joint space distance in the central $80 \%$ of the facet joint. SD: Standard deviation. P: Propability of error of the used t-Test

Table 3: Test performance of the two readers.

\begin{tabular}{|c|c|c|c|c|}
\hline & \multicolumn{2}{|c|}{ Facet pain vs. Controls } & \multicolumn{2}{c|}{ exact localization } \\
\hline & sensitivity & specificity & sensitivity & specificity \\
\hline Reader 1 & 0.93 & 0.87 & 0.53 & 0.87 \\
\hline Reader 2 & 0.87 & 0.87 & 0.4 & 0.8 \\
\hline
\end{tabular}


are good in our study, so that one can conclude with good LR+ and LR- values $[35,36]$ that MRI of the facet joints is a useful investigation to rule in or rule out facet pain. One has to concede, however, that the design of our study with clear cut differences between controls and facet joint pain patients in a neurosurgical outpatient clinic may exaggerate the promise of MRI.

This becomes evident with the more challenging task to correctly identify the locus of the symptomatic facet joint. Here the sensitivity and specificity are much weaker, so that with application of the abovementioned criteria, MRI is not useful to localize the problem under blinded conditions. This might be due to the well-known fact that it is easier to read and to interpret imaging data with the knowledge of the clinical findings than without; a realization of Bayes theorem.

\section{Grading of facet joint degeneration}

Osteophytes have been thought to represent adaptive referably [13], however, our data with significantly higher grading for symptomatic joints point at degenerative changes that may be related to symptoms. Bogduk claims that "This evidence precludes degeneration from being used as a diagnosis for spinal pain." [13]. However, at least in our sample, degenerative changes are correlated with chronic facet joint pain. Thus it is important to grade facet degeneration when reading MRI of the spine in lumbar pain patients.

\section{Size and shape of the facet joint}

Correlating with signs of secondary hypertrophy and degeneration, the size of the joint may be associated with symptoms: Chronic facet joint pain patients tend to have larger joints than controls.

The shape and angle of the facet joint defines it function and also its liability to injury [12]. However, our own data were acquired with good inter-reader variability, but did not show correlation between shape and symptoms.

\section{Facet joint angle}

It has been shown that increased angles might predispose to slippage and degeneration [8]. Our data show larger angles in symptomatic patients. However the correlation of facet joint angles with symptoms is significant only at level L4/5. An ideal angle of $45 \%$ as a compromise of anterior load bearing and stabilization against rotation is shown in our controls at L4/5. In chronic facet joint pain patients, the angle is larger.

\section{Joint space signal and distance}

Intraarticular fluid has been thought to be relevant because it hints at facet joint instability $[21,22]$. This in turn may alter operative approaches to favour stabilization [20] over mere decompression or denervation. However, our data did not show correlation of joint space signal and symptoms.

Joint space distance might hint at degeneration with decreased cartilage layer. The mere joint space distance however has not been associated with symptoms in our cohort.

\section{Validity of the diagnostic tool of medial branch block}

A placebo effect of injections has been described, and indeed, hetero suggestion can be used as a powerful tool to support therapeutic procedures [24]. However, it has been shown that controlled (referably repeated) medial branch blocks are the diagnostic procedure of choice to diagnose facet joint pain $[34,29]$. Thus this procedure was used as the gold standard, against which the MRI measurements were compared. 


\section{LIMITATIONS}

Clearly, the retrospective nature of our study entails the disadvantage not to provide healthy controls, but rather controls with normal MRI. Exclusion criteria were chronic lumbago or facet joint origin of pain. Also the small sample size limits generalizations: We could show differences in our sample-however, the results should ideally be replicated prospectively with a larger sample and healthy controls to provide a reliable evaluation. We did not age match patients and controls, but merely searched for normal MRI scans. Thus the age differences found in our study are due to selection bias and may not be evaluated further. It has been shown that age is the strongest predictor of degeneration [13]. But the symptomatic patients were identified according to the clinical gold standard of controlled anesthetic blocks, so that diagnosis and localization is regarded as robust. Furthermore, age correction was applied in statistical analysis where possible, to correct for age effects.

The inclusion of patients with symptoms related to etiologies other than facet joint pain provides a naturalistic setting and matches real world situations better than inclusion of totally asymptomatic controls.

We had earlier assessed the chronic facet joint patients of this study. The earlier study did not use controls but the contralateral side as a sort of internal comparator. This however was deemed unsatisfactory since only comparison of leading cause for pain with lesser symptomatic joints was possible. Thus the new study with inclusion of controls and new blinding as well as new reading of symptomatic patients was initiated. The time span of a year between both studies was deemed to be sufficient to rule out recall bias and assume correct blinding.

\section{CONCLUSION}

MRI is able to detectsigns that predictfacetjoint pain. Contrary to recent publications, we could demonstrate differences between asymptomatic and symptomatic subjects showing the latter to have larger joints and more signs of degeneration.

One can conclude from the strong LR+ and LR- values that MRI is a useful investigation to rule in or rule out facet pain. However, the exact localization of the cause of pain has not been possible.

\section{REFERENCES}

1. Vos T, Barber RM, Bell B, Bertozzi-Villa A, Biryukov S, et al. Global, regional, and national incidence, prevalence, and years lived with disability for 301 acute and chronic diseases and injuries in 188 countries, 1990-2013: a systematic analysis for the Global Burden of Disease Study 2013. Lancet. 2015; 386: 743-800. Ref.: https://goo.gl/fiJsY9

2. Suman A, Schaafsma FG, Elders PJ, van Tulder MW, Anema JR. Cost-effectiveness of a multifaceted implementation strategy for the Dutch multidisciplinary guideline for nonspecific low back pain: design of a stepped-wedge cluster randomised controlled trial. BMC Public Health. 2015; 15: 522. Ref.: https://goo.gl/NKjhjz

3. Luo X, Pietrobon R, Sun SX, Liu GG, Hey L. Estimates and patterns of direct health care expenditures among individuals with back pain in the United States. Spine (Phila Pa 1976). 2004; 29: 79-86. Ref.: https://goo.gl/YLXzV6

4. Kim KY, Wang MY. Magnetic resonance image-based morphological predictors of single photon emission computed tomography-positive facet arthropathy in patients with axial back pain. Neurosurgery. 2006; 59: 147-156. Ref.: https://goo.gl/8ziWYD

5. Hancock MJ, Maher CG, Latimer J, Spindler MF, McAuley JH, et al. Systematic review of tests to identify the disc, SIJ or facet joint as the source of low back pain. Eur Spine J. 2007; 16: 1539-1550. Ref.: https://goo.gl/KXGUZq

6. Chou R, Hufman LH. Guideline for the Evaluation and Management of Low Back Pain. Evidence Review. American Pain Society, 2015.

7. Lakadamyali $\mathrm{H}$, Tarhan NC, Ergun T, Cakir B, Agildere AM. STIR sequence for depiction of degenerative 
changes in posterior stabilizing elements in patients with lower back pain. AJR Am J Roentgenol. 2008; 191: 973-979. Ref.: https://goo.gl/jRXZzG

8. Gao F, Hou D, Zhao B, Sun X, Sun $\mathrm{H}$, et al. The pedicle-facet angle and tropism in the sagittal plane in degenerative spondylolisthesis: a computed tomography study using multiplanar reformations techniques. J Spinal Disord Tech. 2012; 25: 18-22. Ref.: https://goo.gl/2L6H63

9. Van Kleef $\mathrm{M}$, Vanelderen $\mathrm{P}$, Cohen $\mathrm{SP}$, Lataster $\mathrm{A}$, Van Zundert $\mathrm{J}$, et al. Pain originating from the lumbar facet joints. Pain Pract. 2010; 10: 459-469. Ref.: https://goo.gl/LBDdlo

10. DePalma MJ, Ketchum JM, Saullo T. What is the source of chronic low back pain and does age play a role? Pain Med. 2011; 12: 224-233. Ref.: https://goo.gl/G4bgoq

11. Manchikanti L, Singh V. Review of chronic low back pain of facet joint origin. Pain Physician. 2002 5: 83-101. Ref.: https://goo.gl/nFGKO3

12. Bogduk N, Bogduk N. The zygapophysial joints-detailed structure. Clinical and radiological anatomy of the lumbar spine. Edinburgh; New York, Churchill Livingstone. 2012: 29-27.

13. Bogduk N. Degenerative joint disease of the spine. Radiol Clin North Am. 2012; 50: 613-628. Ref.: https://goo.gl/KcV3qJ

14. Lehman VT, Murthy NS, Diehn FE, Verdoorn JT, Maus TP. The posterior ligamentous complex inflammatory syndrome: spread of fluid and inflammation in the retrodural space of Okada. Clin Radiol. 2015; 70: 528-535. Ref.: https://goo.gl/jUD5tj

15. Revel ME, Listrat VM, Chevalier XJ, Dougados M, N guyen MP, et al. Facet joint block for low back pain: identifying predictors of a good response. Arch Phys Med Rehabil. 1992; 73: 824-828. Ref.: https://goo.gl/KNbv5g

16. NICE. Low back pain (early management): overwiev, Retrieved. 2015. Ref.: https://goo.gl/QgwJ0i

17. Airaksinen O, Brox Jl, Cedraschi C, Hildebrandt J, Klaber-Moffett $\mathrm{J}$, et al. Chapter 4. European guidelines for the management of chronic nonspecific low back pain. Eur Spine J. 2006; 15: 192 300. Ref.: https://goo.gl/2DiWBX

18. Bundesärztekammer (BÄK), KBK, Arbeitsgemeinschaft der Wissenschaftlichen medizinischen Fachgesellschaften (AWMF): Nationale VersorgungsLeitlinie Kreuzschmerz-Langfassung, 1. Auflage. Version 5. 2010, zuletzt verändert, 2015.

19. Maataoui A, Vogl TJ, Middendorp M, Kafchitsas K, Khan MF. Association between facet joint osteoarthritis and the Oswestry Disability Index. World J Radiol. 2014; 6: 881-885. Ref.: https://goo.gl/fub9VK

20. Schinnerer KA, Katz LD, Grauer JN. MR findings of exaggerated fluid in facet joints predicts instability. J Spinal Disord Tech. 2008; 21: 468-472. Ref.: https://goo.gl/jM15Aw

21. Cho BY, Murovic JA, Park J. Imaging correlation of the degree of degenerative L4-5 spondylolisthesis with the corresponding amount of facet fluid. J Neurosurg Spine. 2009; 11: 614-619. Ref.: https://goo.gl/FOvYN5

22. Caterini R, Mancini F, Bisicchia S, Maglione P, Farsetti $P$. The correlation between exaggerated fluid in lumbar facet joints and degenerative spondylolisthesis: prospective study of 52 patients. J Orthop Traumatol. 2011; 12: 87-91. Ref.: https://goo.gl/srhYAF

23. Kettler A, Wilke HJ. Review of existing grading systems for cervical or lumbar disc and facet joint degeneration. Eur Spine J. 2006; 15: 705-718. Ref.: https://goo.gl/1d4PfM

24. Maataoui A, Vogl TJ, Khan MF. Magnetic resonance imaging-based interpretation of degenerative changes in the lower lumbar segments and therapeutic consequences. World J Radiol. 2015; 7: 194 197. Ref.: https://goo.gl/XkxO9z

25. Lehman VT, Murphy RC, Kaufmann TJ, Diehn FE, Murthy NS, et al. Frequency of discordance between facet joint activity on technetium Tc99m methylene diphosphonate SPECT/CT and selection for percutaneous treatment at a large multispecialty institution. AJNR Am J Neuroradiol. 2014; 35: 609614. Ref.: https://goo.gl/ncDqkC

26. Freiermuth $D$, Kretzschmar M, Bilecen D, Schaeren $S$, Jacob AL, et al. Correlation of $(99 \mathrm{~m})$ Tc-DPD SPECT/CT Scan Findings and Diagnostic Blockades of Lumbar Medial Branches in Patients with Unspecific Low Back Pain in a Randomized-Controlled Trial. Pain Med. 2015; 16: 1916-1922. Ref.: https://goo.gl/9ZmwCa

27. Schwarzer AC, Wang SC, O'Driscoll D, Harrington T, Bogduk N, et al. The ability of computed tomography to identify a painful zygapophysial joint in patients with chronic low back pain. Spine (Phila Pa 1976). 1995; 20: 907-912. Ref.: https://goo.gl/Qff45d 
28. Kalichman L, Li L, Kim DH, Guermazi A, Berkin V, et al. Facet joint osteoarthritis and low back pain in the community-based population. Spine (Phila Pa 1976). 2008; 33: 2560-2565. Ref.: https://goo.gl/qRh9bL

29. Stojanovic MP, Engel AJ. An Expedited Diagnostic Algorithm for Lumbosacral Pain: The Best Likelihood Scenario Approach. Pain Med. 2015; 16: 2271-2276. Ref.: https://goo.gl/OgdOs9

30. Bogduk N, International Spine Intervention Society. Standards Committee. Practice guidelines for spinal diagnostic and treatment procedures. San Francisco, International Spine Intervention Society. 2013.

31. Klessinger S, Halatsch M E, Freund W. Retrospective Magnetic Resonance Imaging Evaluation in Patients with Zygapophysial Joint Pain. J Spine Neurosurg. 2015; 4.

32. R Development Core Team R. A language and environment for statistical computing. Vienna, R Foundation for Statistical Computing. 2015.

33. Landis JR, Koch GG. The measurement of observer agreement for categorical data. Biometrics. 1977; 33: 159-174. Ref.: https://goo.gl/YeKm53

34. Bogduk N, Dreyfuss $P$, Govind J. A narrative review of lumbar medial branch neurotomy for the treatment of back pain. Pain Med. 2009; 10: 1035-1045. Ref.: https://goo.gl/hpcx7Y

35. Puig S, Felder-Puig R. [Evidence-based radiology: a new approach to evaluate the clinical practice of radiology]. Fortschr Roentgenstr. 2006; 178: 671-679. Ref.: https://goo.gl/P1CNeK

36. Portney LG, Watkins MP. Chapter 27: Statistical Measures of Validity. Foundations of clinical research: Applications to practice. Upper Saddle River, Prentice Hall Health: 2009; 619-659. 